\title{
GMR
}

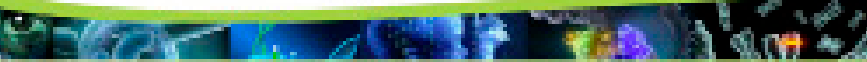

\section{Analysis of HLA-DQB1 allele polymorphisms in Uyghur women with cervical cancer}

\author{
L. Han ${ }^{1,2}$, S. Husaiyin ${ }^{1}$, L. Wang ${ }^{1}$, K.D. Wusainahong ${ }^{1}$, X. Fu³ and M. Niyazi ${ }^{1}$ \\ 'Department of Gynecology, Xinjiang Uyghur Autonomous Region People's Hospital, \\ Urumqi, China \\ ${ }^{2}$ Postgraduate College of Xinjiang Medical University, Urumqi, China \\ ${ }^{3}$ Department of Gynecology, First Affiliated Hospital of Xinjiang Medical University, \\ Urumqi, China
}

Corresponding authors: X. Fu / M. Niyazi

E-mail: xjfx2004@sina.com / mynr68@126.com

Genet. Mol. Res. 14 (4): 17252-17261 (2015)

Received June 23, 2015

Accepted September 30, 2015

Published December 16, 2015

DOI http://dx.doi.org/10.4238/2015.December.16.25

ABSTRACT. In Uyghur women, mortality rates from cervical cancer are amongst the highest in the nation, and genetic susceptibility probably plays a role in the pathogenesis of the disease. We investigated the correlation between polymorphisms of the HLA-DQB1 allele and cervical cancer in Xinjiang Uyghur women. Cervix tissue samples from 80 cases of cervical cancer and 80 cases of cervicitis were genotyped using polymerase chain reaction-sequence-based typing (PCR-SBT) for HLA-DQB1. Two hundred and ninety-six alleles were identified among the 160 cases. One hundred and thirty-six alleles were heterozygous and 24 were homozygous. Using frequency calculations and statistical analysis, we found that HLA-DQB1*0325 (OR: 10.60, 1.341-83.81) and HLA-DQB1*0332 (OR: 12.59, 2.909-54.526) were more frequently identified in the cervical cancer group compared with the cervicitis group $(P<0.05)$. However, HLA-DQB1*0317 (OR: 0.49, 0.3040.798 ) and HLA-DQB1*040302 (OR: $0.40,0.243-0.658$ ) were present less frequently in the cervical cancer group $(P<0.05)$. The frequency of the HLADQB1 genotype in Uyghur was different from that reported previously in other areas. HLA-DQB $1{ }^{*} 0325$ and HLA-DQB1*0332 probably act as cervical cancer susceptibility genes in Uyghur women from Xinjiang. In contrast, HLA- 
DQB1*0317 and HLA-DQB1*040302 may be protective genes.

Key words: Cervical cancer; HLA-DQB1; PCR-SBT; Predisposing genes

\section{INTRODUCTION}

Cervical cancer is the third most common cancer in women and accounts for $13 \%$ of cancers in women in developing countries (Ferlay et al., 2010). The Uyghurs of South Xinjiang exhibit a high incidence of cervical cancer. There is a close correlation between cervical cancer development and persistent infection with high-risk human papilloma virus (HPV). In addition to HPV infection and viral persistence in carcinogenesis, immune surveillance by the host plays a vital role in the control of infection and disease development.

As an antigen-presenting molecule, human leukocyte antigen (HLA) plays an important role in the body's immune surveillance of viruses. Wank and Thomssen (1991) were the first researchers to report a correlation between the HLA2DQ3 antigen and cervical squamous cell carcinoma (CSCC) $(R R=7.1)$ in German women. Ben Othmane et al. (2012) further investigated the correlation between HLA and cervical HPV infection and cervical cancer. Certain HLA-II alleles are associated, to some degree, with cervical cancer (Wu et al., 2006). Specifically, an increase in the frequency of certain alleles may increase genetic susceptibility to the disease, whereas a reduction in the frequency of other HLA alleles may be protective against cervical cancer. Variations in HLA distribution among races and ethnicities have led to variations in the HLA allele frequencies in cervical cancers in various races and ethnicities (Beskow et al., 2005). To date, most studies have demonstrated that $\mathrm{DQB} 1{ }^{*} 03\left(\mathrm{DQB} 1{ }^{*} 0301, \mathrm{DQB} 1^{*} 0302\right.$, and $\left.\mathrm{DQB} 1{ }^{*} 0303\right)$ is positively correlated with cervical cancer and increases its risk (Madeleine et al., 2002). This finding has been confirmed in populations in Norway (Helland et al., 1994), Japan (Nawa et al., 1995), France (Sastre-Garau et al., 1996), and an African American community (Gregoire et al., 1994). One study involving Spanish women in New Mexico also demonstrated that HPV16-positive cervical cancer patients exhibited increased DQB1*0303 expression (Apple et al., 1994). Hildesheim et al. (1998) reported the opposite result in Americans, which indicated the protective effects of $D Q B 1{ }^{*} 03$ and DQB1*0602 against cervical cancer. Similarly, Allen et al. (1996) did not identify a correlation between $\mathrm{DQB1}{ }^{*} 03$ and cervical cancer in Swedish women.

Studies of HLA and immunoglobulins have indicated that the Han Chinese are divided into northern and southern groups, and these groups exhibit similarities and differences in the distribution of HLA and immunoglobulins. Some data have demonstrated that HLA distribution in Xinjiang Uyghurs more closely resembles that in individuals of Caucasian descent, specifically white Americans and Europeans (Lai et al., 1999). An epidemiologic survey of Chinese women with HPV infection and cervical cancer, which was organized by the China Cancer Foundation, indicated that in Xinjiang Uyghur women, cervical cancer occurred at a high prevalence, and was associated with high mortality and low HPV infection. Notably, Uyghur women had cervical cancer earlier in life compared with other ethnic groups: that is, at an average age of 43.4 years compared with 49.9 years in Han women (Peng et al., 2003). The distribution of HPV subtypes in cervical cancer in Xinjiang Uyghurs is different to that in domestic and foreign reports (Guzalnur et al., 2001). The characteristics of cervical cancer and the overall distribution of HLA in Xinjiang Uyghurs are not the same as in Han Chinese and other ethnic groups. These findings suggest a potential effect of genetic predisposition among races. 
In this study, polymerase chain reaction-sequence-based typing (PCR-SBT) was used to identify HLA-DQB1 alleles in 80 cases of CSCC and 80 cases of normal cervical tissue in Xinjiang Uyghur women. The objective was to preliminarily explore the role of genetic susceptibility in this ethnic group.

\section{MATERIAL AND METHODS}

\section{Clinical data}

Eighty Uyghur patients with cervicitis and 80 Uyghur patients with CSCC who were hospitalized at the Department of Gynecology of Xinjiang Uyghur Autonomous Region People's Hospital from August 2009 to April 2010 were enrolled in this study. Their ages ranged from 20 to 60 years. The average ages of the cervicitis and CSCC groups were $49.5( \pm 7.87)$ and $44.1( \pm 8.81)$ years, respectively. No patient had a treatment history of radio- or chemotherapy in either group. All patients were confirmed by pathological diagnosis. The clinical staging and histopathological grading of cervical carcinoma were in accordance with the standards of diagnosis and treatment of cervical carcinoma according to the International Federation of Gynecology (2000). The diagnosis of chronic cervicitis was in accordance with the standards described in Obstetrics and Gynecology (Version 8). The cervicitis types considered included cervical erosion, nabothian cysts, post-coital bleeding, and cervical hypertrophy. The exclusion criteria included the following: 1) abnormal cervical cytology results; 2) pregnancy, suspected pregnancy, or breastfeeding; 3) severe internal complications or psychiatric disorders; 4) diabetes mellitus; 5) gonococcal cervicitis; and 6) other conditions that were not suitable for this study. All enrolled patients signed an informed consent form. All procedures were in accordance with the Declaration of Helsinki and were approved by the Ethics Committee of Xinjiang Uyghur Autonomous Region People's Hospital, China. Fresh cervical carcinoma or benign uterine lesion cervical samples were used. After collection, the samples were placed in cryotubes, frozen in liquid nitrogen, and transferred to a $-80^{\circ} \mathrm{C}$ refrigerator within $24 \mathrm{~h}$. DNA was extracted using the phenol-chloroform method.

\section{HPV genotyping}

HPV genotyping was performed in strict accordance with the HPV gene microarray genotyping kit manufacturer instructions (Kaipu Biotech, Hong Kong, China). The kit takes advantage of Kaipu medical nucleic acid rapid hybridization as the platform; it simultaneously identifies $21 \mathrm{HPV}$ isoforms on a low-density gene chip membrane, which is prefixed with nucleic acid probes based on the principle of flow-through hybridization. The detectable HPV isoforms include 13 high-risk isoforms (HPV16, HPV18, HPV31, HPV33, HPV35, HPV39, HPV45, HPV51, HPV52, HPV56, HPV58, HPV59, and HPV68), five low-risk isoforms (HPV6, HPV11, HPV42, HPV43, and HPV44), and three isoforms that are common among the Chinese Han population. Negative and positive results were determined according to the kit.

\section{Methods}

\section{Primers}

The primers were designed according to http://www.gendx.com/ and were synthe- 
sized by Shanghai Sangon Biological Engineering Technology Services Limited, Shanghai, China. The primer sequences for HLA-DQB1 were 5'-GCGGATCACAAGTCTGGAGC-3' and 5'-CAAGGATGGGCCTCGCAGA-3' with a fragment length of $463 \mathrm{bp}$.

\section{Genomic DNA extraction}

Cellular DNA was extracted from cervical tissue using the tissue/cell Genomic DNA rapid extraction kit (centrifugal column), according to the manufacturer instructions (Beijing Biomed Science and Technology Development Corporation, China).

\section{PCR amplification of the second exon of HLA-DQB1}

Because of the complex structure of the HLA-DQB1 second exon, a two-stage PCR amplification was applied. The PCR amplification system comprised the following: the primers; $1 \mu \mathrm{L}$ deoxyribonucleotide triphosphate (dNTPs); $1 \mu \mathrm{L}$ Taq Buffer; $5 \mu \mathrm{L}$ 10X PCR Buffer (without $\mathrm{Mg}^{2+}$ ); $100 \mathrm{mM}$ Tris- $\mathrm{HCl}\left(\mathrm{pH} 8.8\right.$ at $25^{\circ} \mathrm{C}$ ); $500 \mathrm{mM} \mathrm{KCl}$ and $0.8 \%(\mathrm{v} / \mathrm{v})$ Nonidet P40; $5 \mu \mathrm{L} \mathrm{MgCl} ; 0.5$ $\mu \mathrm{L}$ Taq enzyme; $1 \mu \mathrm{L}$ template, and sterile double-distilled water to obtain a total volume of $50 \mu \mathrm{L}$. The conditions for the first stage of the reaction were as follows: denaturation at $95^{\circ} \mathrm{C}$ for $3 \mathrm{~min} ; 35$ cycles at $94^{\circ} \mathrm{C}$ for $45 \mathrm{~s}, 60^{\circ} \mathrm{C}$ for $35 \mathrm{~s}$, and $72^{\circ} \mathrm{C}$ for $90 \mathrm{~s}$; and a final extension at $72^{\circ} \mathrm{C}$ for $10 \mathrm{~min}$. The product from the first stage $(1 \mu \mathrm{L})$ was used as a template for the second-stage amplification. The reaction conditions for the second-stage amplification were as follows: denaturation at $95^{\circ} \mathrm{C}$ for $3 \mathrm{~min} ; 35$ cycles at $94^{\circ} \mathrm{C}$ for $45 \mathrm{~s}, 58^{\circ} \mathrm{C}$ for $35 \mathrm{~s}$, and $72^{\circ} \mathrm{C}$ for $90 \mathrm{~s}$; and a final extension at $72^{\circ} \mathrm{C}$ for $10 \mathrm{~min}$. The PCR products were identified by gel electrophoresis (Figure 1).

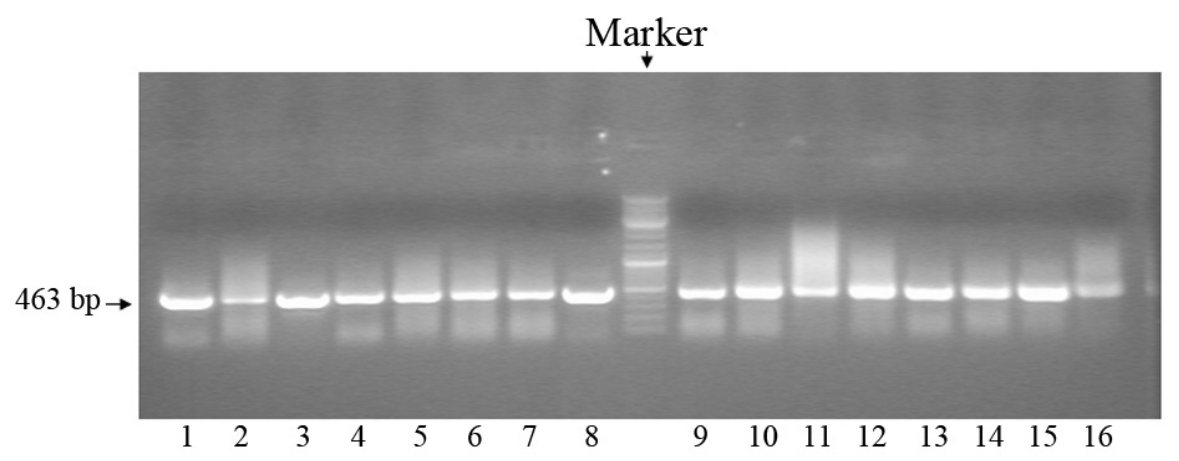

Figure 1. Electrophoretogram of the second exon of HLA-DQB1 after polymerase chain reaction (PCR) amplification. The marker was 100-10,000 bp, and 1-16 represent the amplified samples.

\section{Purification of PCR products and sequencing}

The amplified PCR products were purified using a UNIQ-10 column type DNA Gel Extraction kit (Sangon Biotech, Shanghai, China) and were sent to Shanghai Sangon Biological Engineering Technology Services Ltd. for sequencing.

\section{Genotype determination of HLA-DQB1 alleles}

We used software developed in-house to compare the gene sequencing results with sequences 
from a nucleic acid sequence database to determine the genotypes of the HLA-DQB1 alleles.

\section{Statistical analysis}

The alleles and genotype frequencies of the two groups were calculated and compared. The ORs of the alleles were calculated to estimate the extent to which alleles were correlated with the disease. Comparisons between the two groups were performed using the $\mathrm{X}^{2}$ test. The significance level of a test was set at $\alpha=0.05$.

\section{RESULTS}

\section{Baseline data}

The basic data and behavioral factors of the two groups are compared in Table 1. The two groups exhibited significant differences in age and occupation composition. No significant differences were identified in gravidity, parity, marital history, family cancer history, contraceptive methods, smoking, alcohol consumption, or menarche time.

\begin{tabular}{|c|c|c|c|c|}
\hline Factor & Cancer $(\mathrm{N}=80)$ & Cervicitis $(N=100)$ & Statistics & $\mathrm{P}$ \\
\hline Age (years) & $50.65 \pm 1.28$ & $44.05 \pm 1.14$ & $t=-3.8575$ & 0.0002 \\
\hline \multicolumn{5}{|l|}{ Occupation } \\
\hline Enterprise & $2(2.50 \%)$ & $0(0)$ & - & $0.0121^{*}$ \\
\hline Farmer or herdswoman & $29(36.25 \%)$ & $33(33.00 \%)$ & & \\
\hline Individual operator & $13(16.25 \%)$ & $35(35.00 \%)$ & & \\
\hline Retired & $4(5.00 \%)$ & $1(1.00 \%)$ & & \\
\hline Unemployed & $32(40.00 \%)$ & $31(31.00 \%)$ & & \\
\hline Gravidity & $3.70 \pm 1.61$ & $3.49 \pm 1.58$ & $t=-0.8311$ & 0.4071 \\
\hline Parity & $1.76 \pm 1.06$ & $1.82 \pm 1.15$ & $t=0.3907$ & 0.6965 \\
\hline \multicolumn{5}{|l|}{ Marital history } \\
\hline Divorced & $4(5.06 \%)$ & $3(3.00 \%)$ & $x^{2}=1.042$ & 0.5938 \\
\hline Widowed & $4(5.06 \%)$ & $3(3.00 \%)$ & & \\
\hline Married & $72(89.87 \%)$ & $94(94.00 \%)$ & & \\
\hline \multicolumn{5}{|l|}{ Family cancer history } \\
\hline Yes & $10(12.50 \%)$ & $5(5 \%)$ & $x^{2}=2.501$ & 0.1137 \\
\hline No & $70(87.50 \%)$ & $95(95 \%)$ & & \\
\hline \multicolumn{5}{|l|}{ Contraceptive methods } \\
\hline Condom & $15(18.75 \%)$ & $17(17.00 \%)$ & $x^{2}=4.374$ & 0.2238 \\
\hline Intrauterine device & $22(27.50 \%)$ & $35(35.00 \%)$ & & \\
\hline Sterilization & $8(10.00 \%)$ & $3(3.00 \%)$ & & \\
\hline None & $35(43.75)$ & $45(45.00 \%)$ & & \\
\hline \multicolumn{5}{|l|}{ Smoking } \\
\hline Yes & $1(1.25 \%)$ & $1(1.00 \%)$ & - & $1.0000^{*}$ \\
\hline No & $79(98.75 \%)$ & $99(99.00 \%)$ & & \\
\hline \multicolumn{5}{|l|}{ Alcohol consumption } \\
\hline Yes & $4(5.00 \%)$ & $1(1.00 \%)$ & - & $0.1714^{*}$ \\
\hline No & $76(95.00 \%)$ & $99(99.00 \%)$ & & \\
\hline Menarche time (years of age) & $12.87 \pm 1.56$ & $13.13 \pm 1.61$ & $t=0.9703$ & 0.3334 \\
\hline
\end{tabular}

*Fisher's exact test.

\section{Distribution of HPV infection types in cervical tissue}

In the cervical cancer group, 77 samples were HPV-positive (96\%). Genotype detection identified 15 high-risk HPV genotypes (HPV16, 18, 31, 33, 35, 39, 45, 51, 52, 56, 58, 59, 68, 53, and 
73) and two low-risk HPV genotypes (HPV11 and 42); of these cases, 33 cases showed infection with only HPV16 (44\%), and 20 showed infection with HPV16 that was complicated with other highrisk genotypes (26\%). Among the cases of HPV16 complicated with other high-risk genotypes, HPV56 was the primary form (14 cases; 70\%), followed by HPV33, and HPV58. Infection with HPV16 complicated with a low-risk genotype was identified in seven cases. Sixty-two cases with HPV16 infection (77.5\%) were identified. The results are summarized in Table 2.

Table 2. Distribution of human papillomavirus (HPV) infection genotypes in the cervical cancer samples.

\begin{tabular}{lcccc}
\hline & HPV genotype & Case No. (N) & HPV genotype & Case No. (N) \\
\hline High-risk & HPV16 & 62 & HPV56 & 17 \\
& HPV58 & 13 & HPV33 & 10 \\
& HPV31 & 10 & HPV51 & 8 \\
& HPV52 & 7 & HPV45 & 7 \\
& HPV53 & 6 & HPV18 & 3 \\
& HPV59 & 3 & HPV68 & 2 \\
Low-risk & HPV39 & 3 & HPV42 & 5 \\
\hline
\end{tabular}

Among the cases with combined infections, a double infection was the primary form, followed by a triple infection. A quintuple infection was identified in one case. The results are summarized in Table 3.

\begin{tabular}{lcr}
\multicolumn{2}{c}{ Table 3. Single and multiple infections in the cervical cancer group. } & Positive rate (\%) \\
\hline Infection type & Positive case No. (N) & 64.93 \\
\hline Single infection & 50 & 19.48 \\
Double infection & 15 & 10.39 \\
Triple infection & 8 & 3.89 \\
Tetramerous infection & 3 & 1.31 \\
Quintuple infection & 1 & \\
\hline
\end{tabular}

\section{HLA-DQB1 PCR amplification and base sequencing results}

The second exons of the HLA-DQB1 fragments were amplified from the cervical tissues obtained from 160 Xinjiang Uyghurs women (Figure 2). A total of 296 alleles were identified in the 160 samples, which included those from 136 individuals with heterozygous alleles and 24 individuals with homozygous alleles. Following the frequency calculation and statistical analysis, the frequencies of HLA-DQB1*0325 (OR: 10.60, 1.341-83.81) and HLA-DQB1*0332 (OR: 12.59, 2.909-54.526) in the women with cervical cancer from Xinjiang Uyghur were significantly increased compared with the control group, whereas the frequencies of HLA-DQB1*0317 (OR: 0.49, 0.3040.798 ) and HLA-DQB1*040302 (OR: 0.40, 0.243-0.658) were significantly lower compared with the control group $(P<0.05)$. The statistical results are presented in Table 4 . These findings indicate that the frequencies of the DQB ${ }^{*} 0325$ and ${ }^{*} 0332$ alleles were significantly increased in CSCC (ORs: 10.60 and 12.59 , respectively), whereas the frequencies of the DQB1*0317 and *040302 alleles were significantly lower in cervical cancer patients compared with the control group (ORs: 0.49 and 0.40 , respectively). 


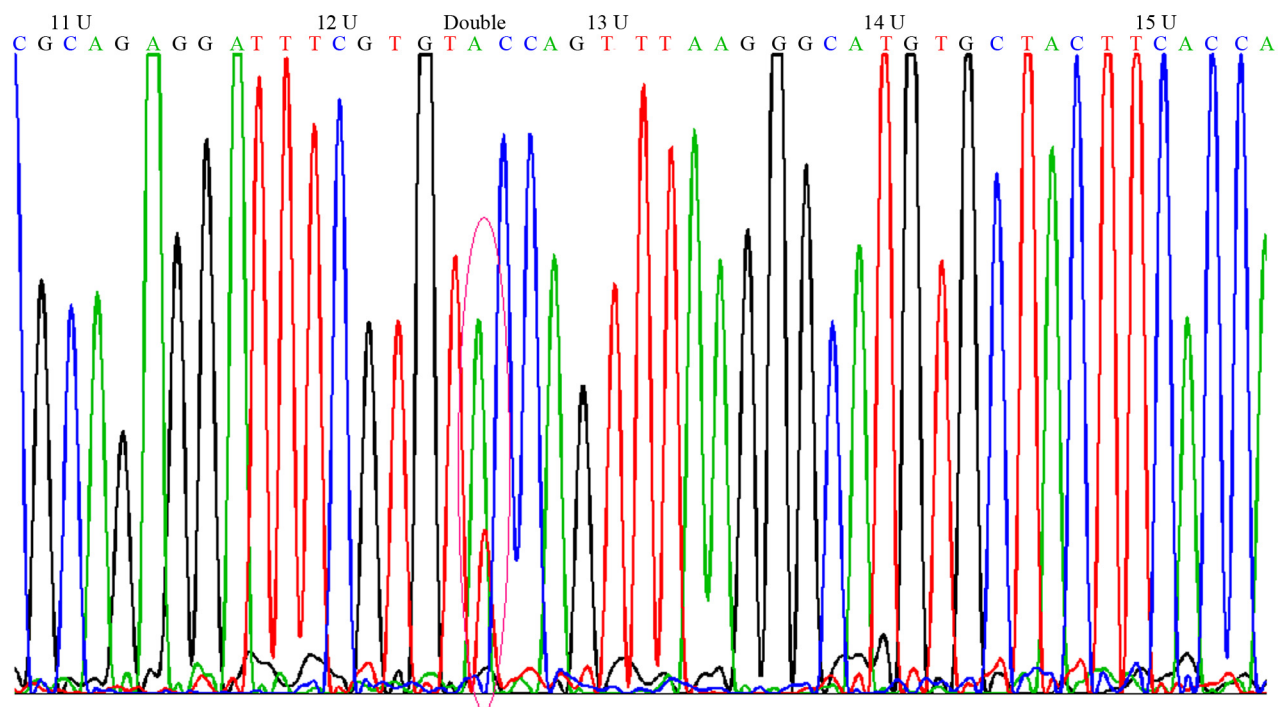

Figure 2. Nucleotide sequencing peaks of the second exon of HLA-DQB1.

\begin{tabular}{|c|c|c|c|c|c|c|c|}
\hline \multirow[t]{2}{*}{ HLA-DQB1 alleles genotype } & \multicolumn{2}{|c|}{ Patient group } & \multicolumn{2}{|c|}{ Control group } & \multirow[t]{2}{*}{$x^{2}$} & \multirow[t]{2}{*}{$P$} & \multirow[t]{2}{*}{ OR, 95\%Cl } \\
\hline & $\begin{array}{c}\text { Number of cases } \\
\qquad N=80\end{array}$ & $\begin{array}{c}\text { Frequency } \\
\text { of alleles }(\%)\end{array}$ & $\begin{array}{c}\text { Number of cases } \\
\qquad N=80\end{array}$ & $\begin{array}{c}\text { Frequency } \\
\text { of alleles }(\%)\end{array}$ & & & \\
\hline DQB1*030303 & 3 & 18.75 & 0 & 0 & & NS & \\
\hline DQB1*0325 & 10 & 6.25 & 1 & 0.63 & 7.626 & 0.006 & $10.60,1.341-83.81$ \\
\hline DQB1*0333 & 33 & 20.63 & 17 & 10.63 & 6.068 & 0.14 & $2.17,1.162-4.112$ \\
\hline DQB1*030501 & 1 & 6.25 & 0 & 0 & & NS & \\
\hline DQB1*0330 & 1 & 0.63 & 0 & 0 & & NS & \\
\hline DQB1*0305 & 3 & 1.88 & 4 & 2.5 & & NS & \\
\hline DQB1*0403 & 3 & 1.88 & 4 & 2.5 & & NS & \\
\hline DQB1*030504 & 1 & 0.63 & 0 & 0 & & NS & \\
\hline DQB1*0317 & 38 & 23.75 & 62 & 38.75 & 8.378 & 0.004 & $0.49,0.304-0.798$ \\
\hline DQB1*0332 & 22 & 13.75 & 2 & 1.25 & 18.018 & 0.000 & $12.59,2.909-54.526$ \\
\hline DQB1*0404 & 6 & 3.75 & 4 & 2.5 & & NS & \\
\hline DQB1*040301 & 2 & 1.25 & 3 & 1.88 & & NS & \\
\hline DQB1*040302 & 33 & 20.63 & 63 & 39.38 & 13.393 & 0.000 & $0.40,0.243-0.658$ \\
\hline DQB1*040201 & 2 & 1.25 & 0 & 0 & & NS & \\
\hline DQB1*050302 & 2 & 1.25 & 0 & 0 & & NS & \\
\hline
\end{tabular}

\section{DISCUSSION}

As in other races and nationalities, in the Uyghur population, cervical cancer is closely related to high-risk HPV and is dominated by HPV16 infection (Guzalnur et al., 2007). Although HPV infection is the main cause of cervical cancer, it does not necessarily lead to cytological abnormalities. The development of cervical cancer is a complex process that is multifactorial and comprises many stages. During carcinogenesis, in addition to HPV infection and the persistence of the virus, other factors may be involved in the development of pathological and histological changes in the cervical epithelium that may contribute to cervical cancer. These factors include 
the activation of oncogenes, the deactivation of tumor suppressor genes, the role of carcinogenic agents, the body's immune response, smoking, oral contraceptive use, environmental factors, and the genetic background of the host (Castro et al., 2009; Ferreira et al., 2010).

As a component of the body's immunological and genetic composition, HLA plays an important role in the occurrence and development of cervical cancer (Mehta et al., 2008; de Araujo et al., 2009). Studies from various countries have demonstrated that the frequency of certain HLA alleles increases in cervical cancer cases in some ethnicities and may correlate with genetic susceptibility (de Araujo et al., 2008; Hernández-Hernández et al., 2009; Kohaar et al., 2009). In contrast, the reduced frequency of certain alleles may prevent the development of cervical cancer (Castro et al., 2007; Eiguchi et al., 2008). The distributions of HLA, which represents the best genetic marker across populations, are different among races and regions, and the reasons for these differences may be multifactorial: differences in HLA distribution among different populations, selection of HLA genotyping methods, types of HPV susceptibility, environmental masking effects, diet, and behavior, for example. Taken together, these factors may contribute to the different frequencies of HLA alleles in cervical cancer cases in different races and ethnic groups (Castro et al., 2007; Guzalnur et al., 2008). Sun et al. (2009) reported that DQB1*0602 might be a protective gene in cervical cancer in Xinjiang Uyghur women. However, in a study of HLA-DQB1 allele detection, which assessed 126 cases of cervical cancer from the Second Affiliated Hospital of Sun Yat-sen University and 98 normal controls using the PCR-SBT method, Liang et al. (2008) demonstrated that $\mathrm{DQB} 1^{*} 030302$ and $\mathrm{DQB} 1{ }^{*} 050301$ were positively related to cervical cancer and represented potential predisposing genes for cervical cancer.

In this study, we used PCR-SBT for the detection and genotyping of the second exon of HLA-DQB1 and demonstrated that the frequencies of DQB1*0325 and DQB1 ${ }^{*} 0332$ were significantly increased in Xinjiang Uyghur women with cervical cancer compared with the control group. Individuals who carry these two alleles may be more susceptible to persistent HPV infection, which suggests that these alleles are predisposing genes for cervical cancer in Xinjiang Uyghur women. The frequencies of DQB $1^{*} 0317$ and $\mathrm{DQB} 1^{*} 040302$ were significantly lower compared with the control group; the presence of these two alleles may enhance the body's ability to clear HPV, which suggests that they protect against cervical cancer in Xinjiang Uyghur women. The results of this study are different from those previously described, probably owing to regional and ethnic differences. Furthermore, the methods applied in the different studies may have also led to substantially different findings. Finally, because many HLA alleles exist, a small sample size could also have led to differential findings.

HLA alleles are related to differences in genetic background. The results from the present study indicate that HLA-DQB1 alleles are relatively concentrated in Xinjiang Uyghur women and mainly include the HLA-DQB1*03 and DQB1*04 serotypes. Wang et al. (2006) tested HLA-DQB1 alleles in the whole blood from 700 individuals from South China and 320 individuals from North China; the findings indicated that the HLA-DQB1 alleles were predominately HLA-DQB1*02, DQB1 ${ }^{*} 03$, and DQB ${ }^{*} 05$ in North China, whereas HLA-DQB1*03, DQB1*05, and DQB1*06 predominated in South China. According to the literature, HLA-DQB1*03 may protect against cervical cancer in Uyghur women (Chan et al., 2007; Guzalinuer et al., 2010). However, our results indicated that HLA-DQBI*0325 and HLA-DQBI ${ }^{*} 0332$ were probably predisposing genes for cervical cancer, and HLA-DQBI ${ }^{*} 0317$ and HLA-DQBI*040302 were probably protective genes. This discrepancy may be caused by regional differences in the investigated populations and differences in the methods used in these studies. The small sample size of this study may also be one reason for the identified differences. 
This study has the following limitations. First, the sample size was small, which may have caused bias in the obtained results, considering the investigated HAL alleles were relatively frequent. Therefore, studies with larger sample sizes would be informative. Second, this study did not include healthy women in the control group because they are unwilling to undergo a cervical biopsy.

In conclusion, the results of this study suggest a link between some genotypes of HLADQB1 and the high incidence of cervical cancer. However, these findings require further investigation to identify the susceptibility genotypes that are of real significance in terms of preventing cervical cancer via early prediction and for reducing its incidence and mortality.

\section{Conflicts of interest}

The authors declare no conflict of interest.

\section{ACKNOWLEDGMENTS}

The authors thank the colleagues from the Department of Gynecology of Xinjiang Uyghur Autonomous Region People's Hospital for their assistance during the work.

\section{REFERENCES}

Allen M, Kalantari M, Ylitalo N, Pettersson B, et al. (1996). HLA DQ-DR haplotype and susceptibility to cervical carcinoma: indications of increased risk for development of cervical carcinoma in individuals infected with HPV 18. Tissue Antigens 48: 32-37.

Apple RJ, Erlich HA, Klitz W, Manos MM, et al. (1994). HLA DR-DQ associations with cervical carcinoma show papillomavirustype specificity. Nat. Genet. 6: 157-162.

Ben Othmane Y, Ghazouani E, Mezlini A, Lagha A, et al. (2012). HLA class II susceptibility to cervical cancer among Tunisian women. Bull. Cancer 99: 81-86.

Beskow AH, Engelmark MT, Magnusson JJ and Gyllensten UB (2005). Interaction of host and viral risk factors for development of cervical carcinoma in situ. Int. J. Cancer 117: 690-692.

Castro FA, Haimila K, Pasanen K, Kaasila M, et al. (2007). Geographic distribution of cervical cancer-associated human leucocyte antigens and cervical cancer incidence in Finland. Int. J. STD AIDS 18: 672-677.

Castro FA, Haimila K, Sareneva I, Schmitt M, et al. (2009). Association of HLA-DRB1, interleukin-6 and cyclin D1 polymorphisms with cervical cancer in the Swedish population - a candidate gene approach. Int. J. Cancer 125: 1851-1858.

Chan PK, Cheung JL, Cheung TH, Lin CK, et al. (2007). HLA-DQB1 polymorphisms and risk for cervical cancer: a case-control study in a southern Chinese population. Gynecol. Oncol. 105: 736-741.

de Araujo Souza PS, Maciag PC, Ribeiro KB, Petzl-Erler ML, et al. (2008). Interaction between polymorphisms of the human leukocyte antigen and HPV-16 variants on the risk of invasive cervical cancer. BMC Cancer 8: 246.

de Araujo Souza PS, Sichero L and Maciag PC (2009). HPV variants and HLA polymorphisms: the role of variability on the risk of cervical cancer. Future Oncol. 5: 359-370.

Eiguchi K, Tatti S, Alonio LV, González JV, et al. (2008). Association of DRB1 and DQB1 HLA class Il polymorphisms in highgrade and neoplastic cervical lesions of women from Argentina. J. Low. Genit. Tract. Dis. 12: 262-268.

Ferlay J, Shin HR, Bray F, Forman D, et al. (2010). Estimates of worldwide burden of cancer in 2008: GLOBOCAN 2008. Int. J. Cancer 127: 2893-2917.

Ferreira da Silva I, Koifman RJ, Quinto Santos Souza C, Ferreira de Almeida Neto O, et al. (2010). TP53 genetic polymorphisms and environmental risk factors associated with cervical carcinogenesis in a cohort of Brazilian women with cervical lesions. J. Toxicol. Environ. Health A 73: 888-900.

Gregoire L, Lawrence WD, Kukuruga D, Eisenbrey AB, et al. (1994). Association between HLA-DQB1 alleles and risk for cervical cancer in African-American women. Int. J. Cancer 57: 504-507.

Guzalinuer A, Mihrinsa A, Zhang SQ, Li H, et al. (2010). Association between HPV infection and HLA-DQB1 alleles polymorphism in the cervical carcinogenesis in Uyghur women in southern Xinjiang. Chin. J. Oncol. 32: 492-496.

Guzalnur A, Lin W and Peng ZL (2001). Detection of human papillomavirus in cervical carcinoma in Uyghur women from 
Xinjiang Uyghur Aotonomy Region. Practical J. Cancer 16: 271-274.

Guzalnur A, Cheng JX and Mikaram (2007). The spectrum of HPV infection in Xinjiang Uyghur women with cervical cancer. Tumor 27: 379-382.

Guzalnur A, Lu L and Mihrgul A (2008). The relationship between race and susceptibility to cervical cancer in Uyghur women in southern Xinjiang. Chin. J. Clin. Oncol. 35: 629-632.

Helland A, Børresen AL, Kristensen G and Rønningen KS (1994). DQA1 and DQB1 genes in patients with squamous cell carcinoma of the cervix: relationship to human papillomavirus infection and prognosis. Cancer Epidemiol. Biomarkers Prev. 3: 479-486.

Hernández-Hernández DM, Cerda-Flores RM, Juárez-Cedillo T, Granados-Arriola J, et al. (2009). Human leukocyte antigens I and II haplotypes associated with human papillomavirus 16-positive invasive cervical cancer in Mexican women. Int. J. Gynecol. Cancer 19: 1099-1106.

Hildesheim A, Schiffman M, Scott DR, Marti D, et al. (1998). Human leukocyte antigen class I/II alleles and development of human papillomavirus-related cervical neoplasia: results from a case-control study conducted in the United States. Cancer Epidmiol. Biomarkers Prev. 7: 1035-1041.

Kohaar I, Hussain S, Thakur N, Tiwari P, et al. (2009). Association between human leukocyte antigen class II alleles and human papillomavirus-mediated cervical cancer in Indian women. Hum. Immunol. 70: 222-229.

Lai SP, Ren HM, Hu HT, Li SB, et al. (1999). HLA-DRB alleles polymorphism in Han, Hui, Uygur and Tibetan populations in northwestern China. Yi Chuan Xue Bao. 26: 447-457.

Liang J, Xu A, Xie Y, Awonuga AO, et al. (2008). Some but not all of HLA-Il alleles are associated with cervical cancer in Chinese women. Cancer Genet. Cytogenet. 187: 95-100.

Madeleine MM, Brumback B, Cushing-Haugen KL, Schwartz SM, et al. (2002). Human leukocyte antigen class II and cervical cancer risk: a population-based study. J. Infect. Dis. 186: 1565-1574.

Mehta AM, Jordanova ES, Kenter GG, Ferrone S, et al. (2008). Association of antigen processing machinery and HLA class I defects with clinicopathological outcome in cervical carcinoma. Cancer Immunol. Immunother. 57: 197-206.

Nawa A, Nishiyama Y, Kobayashi T, Wakahara Y, et al. (1995). Association of human leukocyte antigen-B1*03 with cervical cancer in Japanese women aged 35 years and younger. Cancer 75: 518-521.

Peng YH, Lalay S, Zhou K, Wang ZH, et al. (2003). Clinical analysis of 4505 cases of cervical cancer. Chin. J. Obstetrics Gynecol. 12: 764-765.

Sastre-Garau X, Loste MN, Vincent-Salomon A, Favre M, et al. (1996). Decreased frequency of HLA-DRB1 13 alleles in Frenchwomen with HPV-positive carcinoma of the cervix. Int. J. Cancer 69: 159-164.

Sun Q, Qi CH and Yang AQ (2009). Correlation of HLA DRB1*1501 and DQB1*0602 with HPV infection and cervical cancer in Xinjiang Uyghur and Han populations. J. Shihezi Univ. (Nat. Sci.) 27: 133-137.

Wang H, Wu DL, Shen AD, Chen CY, et al. (2006). With genechip technique to investigate HLA-DQB1 gene polymorphisms in south and north regions of China. Zhonghua Yi Xue Yi Chuan Xue Za Zhi. 23: 238-239.

Wank R and Thomssen C (1991). High risk of squamous cell carcinoma of the cervix for women with HLA-DQw3. Nature 352 : 723-725.

Wu Y, Chen Y, Li L, Yu G, et al. (2006). Analysis of mutations in the E6/E7 oncogenes and L1 gene of human papillomavirus 16 cervical cancer isolates from China. J. Gen. Virol. 87: 1181-1188. 